\title{
Stress field determination from local stress measurements by numerical modelling
}

\author{
$\operatorname{AUTHOR}(\mathrm{S}):$ \\ LI, G; MIZUTA, Y; ISHIDA, T; LI, H; NAKAMA, S; SATO, \\ $\mathrm{T}$
}

\section{CITATION:}

LI, G ...[et al]. Stress field determination from local stress measurements by numerical modelling. International Journal of Rock Mechanics and Mining Sciences 2009, 46(1): 138 147

ISSUE DATE:

2009-01

URL:

http://hdl.handle.net/2433/123420

\section{RIGHT:}

Copyright (c) 2008 Elsevier; This is not the published version. Please cite only the published version.; この論文は出版社版でありません。引用の 際には出版社版をご確認ご利用ください。 


\title{
Stress field determination from local stress measurements by numerical modeling
}

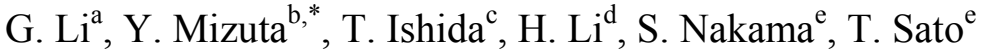 \\ ${ }^{a}$ Mewbourne School of Petroleum \& Geological Engineering, The University of Oklahoma,73019-1004,USA \\ ${ }^{b}$ Department of Eco Design, Faculty of Engineering, Sojo University, Kumamoto, 860-0082, Japan \\ ${ }^{c}$ Department of Civil and Earth Resources Engineering, Kyoto University, Katsura, Nishikyo-ku, Kyoto, 615-8540, Japan \\ ${ }^{d}$ Carbon \& Energy Management, Alberta Research Council, Canada, T6N 1 E4 \\ ${ }^{e}$ Japan Atomic Energy Agency, Mizunami, Gifu, 509-6132, Japan
}

Accepted

\begin{abstract}
A back analysis using a three dimensional boundary element method can be used to calculate the far-field stress state from local stresses measured in situ. The far-field stresses are decomposed into tectonic and gravitational components and account for the influence of localized faulting and topography. Therefore, the far-field stresses are taken to consist of a constant term, a term that varies linearly with depth, and a hyperbolic term, with one of the principal stresses being vertical. A boundary element method for inhomogeneous bodies is introduced to calculate elastic gravitational stresses, which is necessary for determination of the far-field stresses.

An application to the stress field determination for the Mizunami Underground Research Laboratory (MIU) is carried out. Based upon the local stresses generally measured by conventional hydraulic fracturing (HF), the unknown stress state at MIU is estimated and compared with the measurements carried out recently by the improved HF method with flow rate measurements at the position of straddle packer. After calculating the far-field stress state by BEM back analysis, 3D-FDM forward analysis was carried to calculate the in situ stresses at certain locations. The 3D-FDM results roughly coincide with the measured results.

Keywords: Stress determination; Stress measurement; Numerical modelling; Boundary element method; Hydraulic fracturing
\end{abstract}

\section{Introduction}

In many civil and mining engineering projects, especially those involving underground excavation, the initial state of stress, i.e., the state of stress prior to any excavation or construction, can be essential to understand. This state may be complex owing to (a) heterogeneity in rock type and rock structure, and (b) the geologic history. Recent experience with underground research laboratories has highlighted the necessity of understanding the ambient stress state for designing and constructing repositories for high-level radioactive wastes, especially with regard to excavation stability and hydraulic suitability. Such projects require stress evaluations for rock masses with widths of several kilometres and depths greater than one kilometre [1]. In some cases the rock at the depth of repository candidates is influenced substantively by topography. Analytical solutions for stresses exist for a range of idealized 2D topographies [2], but accurate analytical solutions are not available for an elastic medium with an irregular three-dimensional surface. Such terrains may be analyzed with numerical models, such as finite difference methods (FDM) or finite element (FEM) methods. A problematic aspect of both these methods, however, is that the model boundary conditions are applied to boundaries of arbitrarily defined geometry, and it is not clear what these should be. Hence, the central question is how the boundary conditions of a numerical model of a rock mass should be assigned. In comparison, boundary element methods (BEM) have the advantages that no artificial truncated boundaries are necessary and open regions deep underground can be treated rather accurately.

We present here a non-linear numerical inverse method for evaluating the in situ state of stress in a rock mass. It accounts for tectonic stresses, topography and rock mass inhomogeneity. Unlike back analysis by FEM or FDM with strain components or displacement components on model boundaries adopted as unknowns, we carried out a back analysis by using the boundary element method (BEM) and treated the far field stress state as the unknown. The BEM back analysis results can then serve as the input boundary conditions for FEM or FDM analysis, two popular and powerful methods well-suited for non-linear or large- strain problems. With the numerical model boundary conditions determined, we can easily study a variety of key issues, such as excavation-induced stress or the stress perturbations caused by faults. Finally, we applied this method to evaluate the stress field of the Tono district, Japan, a candidate for an underground repository site for high-level radioactive wastes. The numerical model is $2.4 \mathrm{~km} \times 3.2 \mathrm{~km}$ in area. Stress measurements in 9 different locations obtained by various methods were adopted for the back analysis. 


\section{Overview of methods}

\subsection{Back analysis}

The in situ stress field can never be completely measured, and as a result methods for evaluating it involve simplifying assumptions. The most common practice is to assume lateral confinement (i.e., no horizontal displacement anywhere due to gravitational loading). The following equation usually is used to describe the initial state of stress in a uniform soil or rock mass below a horizontal free surface:

$$
\sigma_{z z}^{0}=\rho g h, \sigma_{x x}^{0}=\sigma_{y y}^{0}=\frac{v}{1-v} \rho g h
$$

where $\rho$ is the mass density of the material, $g$ is the gravitational acceleration, $v$ is Poisson's ratio, and $h$ is the elevation below the surface which assumes a negative value [3]. The terms $\sigma_{a x x}^{0}$ and $\sigma_{y y}^{0}$ are the two horizontal principal stresses, and $\sigma_{z z}^{0 x}$ is the vertical stress at depth $h$. Actual field measurements, however, show that the horizontal stresses commonly to not follow this relationship, and in many places are several times larger than the vertical stress [4]. Furthermore, the horizontal stress state is not uniform, especially in a seismically active region such as Japan [5]. The current stress state reflects a series of geologic events, the stiffness of a rock mass, as well as gravitational and tectonic stresses [6]. Finally, a rock mass heterogeneities and discontinuities cause local stress variations. In light of these factors, the assumption of lateral confinement is likely to be inappropriate in many cases, and factors like tectonic stresses must be considered.

The following equation provides a more general relationship, with the constraints that one of the principal stress components is vertical and varies linearly with depth:

$\sigma^{0}=S+\alpha \rho g h+\frac{b}{h+a} k \rho g h$

where

$$
\begin{array}{ccc}
\sigma^{0} & =\left[\begin{array}{ccc}
\sigma_{x x}^{0} & \sigma_{x y}^{0} & 0 \\
\sigma_{y x}^{0} & \sigma_{y y}^{0} & 0 \\
0 & 0 & \sigma_{z z}^{0}
\end{array}\right] & S=\left[\begin{array}{ccc}
S_{x x} & S_{x y} & 0 \\
S_{y x} & S_{y y} & 0 \\
0 & 0 & 0
\end{array}\right] \\
\alpha & =\left[\begin{array}{ccc}
\alpha_{x x} & 0 & 0 \\
0 & \alpha_{y y} & 0 \\
0 & 0 & \alpha_{z z}
\end{array}\right] \quad k=\left[\begin{array}{ccc}
k_{x x} & k_{x y} & 0 \\
k_{y x} & k_{y y} & 0 \\
0 & 0 & 0
\end{array}\right]
\end{array}
$$

Here $\sigma^{0}$ stands for the in situ measured stress state, $S$ is the tectonic (regional) stress state, $\alpha$ is the 3-by-3 matrix of coefficients due, to gravitational loading with the relation that $\alpha_{x}=\alpha_{y}=\frac{}{}$ and $\alpha_{z}=1, k$ is the 3-by-3 matrix of coefficients for - a $Y$ inear distribution of horizontal stresses [7], and $a$ and $b$ are constants, determined from measured data by a simplex method, that allow for a non-linear distribution of certain stresses with depth [4]. In this equation $a$ has a dimension of length and $b$ is dimensionless. We emphasize that $S_{x}, S_{y}, \quad S_{x y}, \alpha_{x}, \alpha_{y}, \alpha_{z}, k_{x}, k_{y}, k_{x y}$ are considered as coefficients of far field stress components. The right side of Equation (2) contains a constant term, a term that varies linearly with $_{b} \mathrm{~h}$, and a non-linear term with a hyperbolic coefficient 1 . As mentioned later, the values of $a=904.6$ meters and $b=812.1$ meters were determined to minimize the sum of the differences of the stress values given by Equation (2) and the stress values measured.

The calculated stress component $\sigma_{i j}^{c}$ at an arbitrary point can be expressed as

$$
\sigma_{i j}^{c}=\beta_{i j, p q} S_{p q}+\gamma_{i j, p q} \alpha_{p q}+\lambda_{i j, p q} k_{p q}
$$

where the superscript $c$ refers to a stress component calculated at that point and repeated indices imply summation. $\beta_{i j, p q}$, $\gamma_{i j, p q}$ and $\lambda_{i j, p q}$ are calculated stress components due to each independent unit stress state established by the coefficients of far field stress components $S_{p q}, \alpha_{p q}$ and $k_{p q}$ respectively. If the measured stress component at an arbitrary point is expressed as $\sigma_{i j}^{m}$, the following equation is obtained by putting $\sigma_{i j}^{m}=\sigma_{i j}^{c}$ in Equation (3)

$\sigma_{i j}^{m}=\beta_{i j, p q} S_{p q}+\gamma_{i j, p q} \alpha_{p q}+\lambda_{i j, p} k_{p q}$

Thus, applying Equation (4) to all stress components at all measurement points, we can obtain the equation relating all field measurement stress components with the unknown coefficients of far field stresses.

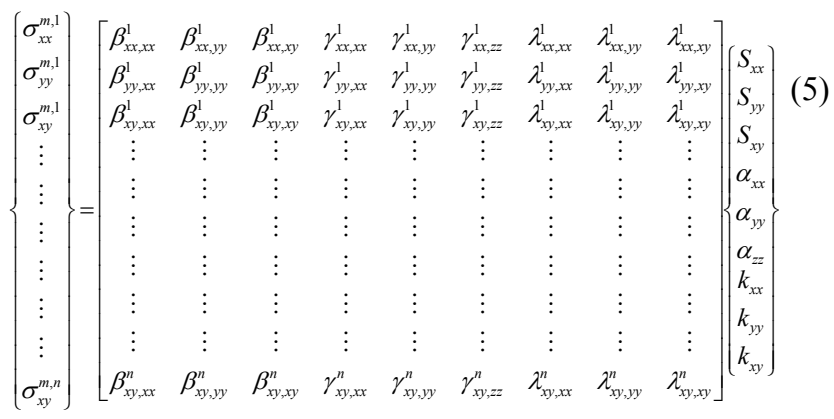

In Equation (5), the superscript $n$ in the last row of the left column stands for the number of underground measurement points, and the superscript $m$ means that the stresses in the left column are all field measurement stress components. Since in practice the number of equations is usually more than 6 , i.e., the number of the unknown coefficients $S_{x}, S_{y}, S_{x y}, k_{x}$, $k_{y}$ and $k_{x y}$, a unique solution cannot be guaranteed. A leastsquares procedure is adopted here to find the best solution of the equation.

2.2 Calculating elastic gravitational stresses by introduction of a boundary element method for inhomogeneous bodies 
To calculate $\beta_{i, p q}, \gamma_{i j, p q}$ and $\lambda_{i j, p q}$ in Equation (5) at an arbitrary point due to each independent unit stress state, numerical modelling is necessary for terrains with an irregular three-dimensional surface, as discussed above. Thus the central question is how to assign boundary conditions to the model of a rock mass. In general, the finite element method (FEM) and finite difference method (FDM) are more popular than the boundary element method (BEM) for dealing with intricate geological conditions (e.g., inelasticity, heterogeneity, and anisotropy). However, certain artificial boundary conditions have to be assumed for FEM and FDM such as prescribed displacement boundary conditions or prescribed stress boundary conditions, and it is hard to evaluate the potential influence of the boundary on the calculated model.

The boundary element method, on the other hand, is well suited for unbounded problems such as excavations or constructions in rock mass since no artificial boundaries are necessary; furthermore, it saves time in numerical modelling since the geometrical dimension is reduced by one. [8]. Boundary element methods include the fictitious stress method (FSM), displacement discontinuity indirect method (DDM), and the direct boundary integral method [9]. The indirect methods were extended by Kuriyama and Mizuta $[10,11]$ to establish three-dimensional procedures using triangular leaf elements. Martel and Muller [12] showed how the displacement discontinuity boundary element method can be used to calculate elastic gravitational stresses beneath topographic surfaces by modeling the topographic surface as a large traction-free crack. They implemented the approach in two-dimensional plane-strain analyses in homogeneous bodies but noted that the method could be extended to three dimensions.

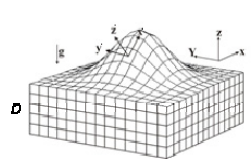

(a)

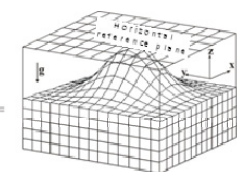

(b)

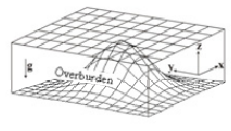

(c)
Figure 1. Conceptual model for calculating the stress state with a topographic surface (The depth $D$ is actually infinite): (a) the stress state under the topographic surface tiled with boundary elements; (b) the ambient stress state under the assumed horizontal reference plane; (c) the perturbation due to the overburden.

To meet needs for large underground excavations or constructions, we present a three-dimensional boundary element method for calculating elastic gravitational stresses for a homogeneous rock mass. Figure 1 shows a conceptual model for calculating the stress state in a homogeneous linear elastic region with a topographic surface. Considering principles of linear elastic theory and continuum mechanics, we assume a horizontal arbitrary plane above the highest elevation of the surface. Anything under this plane is assumed as one homogeneous linearly elastic body. The stress state at an arbitrary point under the topographic surface can be calculated by subtracting the perturbation to the ambient stress state due to the overburden between the horizontal arbitrary plane and the surface, from the ambient stress state under the assumed horizontal reference plane. The total stresses are obtained as the sum of the ambient stresses state and the perturbation to it, for example,

$\left(\sigma_{x^{*} x^{*}}^{i}\right)_{\mathrm{t}}=\left(\sigma_{x^{*} x^{*}}^{i}\right)_{\text {in }}+\left(\sigma_{x^{*} x^{*}}^{i}\right)_{0}$

where $\left(\sigma_{*^{*} z^{*}}^{i}\right),\left(\tau_{*^{*} z^{*}}^{i}\right),\left(\tau_{z^{*} x^{*}}^{i}\right)$ are equal to zero for the free topographic surface. An initial stress state under the assumed horizontal arbitrary plane prior to removal of the overburden can be calculated analytically using Equation (2). The perturbation stresses due to the overburden from the arbitrary plane to the topographic surface can be easily solved with the adoption of fictitious stresses. Here body forces are described in a global coordinate system where the $\mathrm{z}$-axis is vertical. The topographic surface stresses are described by an elementbased local co-ordinate system. The origin of the local coordinate system is at the centre of the element, with $z^{*}$-axis normal to the element. In this approach the effect of horizontal ambient stresses is established by $S_{x}, \quad S_{y}, \quad S_{x y}, \alpha_{x}, \alpha_{y}, k_{x}, k_{y}, k_{x y}$. For any boundary element $i$ along the topographic surface, the following equation can be set up

$$
\left.\begin{array}{l}
\left(\sigma_{z^{*} z^{*}}^{i}\right)_{\text {in }}=\sum_{j=1}^{N} A_{z^{*} x^{*}}^{i j} P_{x^{*}}^{j}+\sum_{j=1}^{N} A_{z^{*} y^{*}}^{i j} P_{y^{*}}^{j}+\sum_{j=1}^{N} A_{z^{*} z^{*}}^{i j} P_{z^{*}}^{j} \\
\left(\tau_{y^{*} z^{*}}^{i}\right)_{\text {in }}=\sum_{j=1}^{N} A_{y^{*} z^{*} x^{*}}^{i j} P_{x^{*}}^{j}+\sum_{j=1}^{N} A_{y^{*} z^{*} y^{*}}^{i j} P_{y^{*}}^{j}+\sum_{j=1}^{N} A_{y^{*} z^{*} z^{*}}^{i j} P_{z^{*}}^{j} \\
\left(\tau_{z^{*} x^{*}}^{i}\right)_{\text {in }}=\sum_{j=1}^{N} A_{x^{*} z^{*} x^{*}}^{i j} P_{x^{*}}^{j}+\sum_{j=1}^{N} A_{x^{*} z^{*} y^{*}}^{i j} P_{y^{*}}^{j}+\sum_{j=1}^{N_{l}} A_{x^{*} z^{*} z^{*}}^{i j} P_{z^{*}}^{j}
\end{array}\right\}
$$

where $P_{x^{*}}^{j}, P_{y^{*}}^{j}, P_{z^{*}}^{j}$ are fictitious stresses introduced to facilitate ${ }^{x}$ the numerical solution to the problem and are fictitious quantities, $A^{i j}$ is the influence coefficient relating the effect of a unit fictitious stress at element $j$ to the traction at element $i, N$ is the total number of the boundary elements, and $\left(\sigma_{z^{*} z^{*}}\right)_{\text {in }},\left(\tau_{x^{*} z^{*}}^{i}\right)_{\text {in }},\left(\tau_{z^{*} x^{*}}^{i}\right)_{\text {in }}$ are the stress components induced by the fictitious stresses at all $N$ elements. On the other hand, since

$\left.\begin{array}{c}\left(\sigma_{z^{*} z^{*}}^{i}\right)_{\text {in }}=-\sigma_{z^{*} z^{*}}^{i} \\ \left(\tau_{y^{*} z^{*}}^{i}\right)_{\text {in }}=-\tau_{y^{*} z^{*}}^{i} \\ \left(\tau_{z^{*} x^{*}}^{i}\right)_{\text {in }}=-\tau_{z^{*} x^{*}}^{i}\end{array}\right\}$

where $\sigma_{z^{*} z^{*}}^{i}, \tau_{y^{*} z^{*}}^{i}, \tau_{z^{*} x^{*}}^{i}$ are the three components of the initial ambient stresses at element $i$, and can be determined by the depth from the assumed arbitrary plane and inclination of the element. Thus we obtain a system of $3 N$ algebraic equations with $3 N$ fictitious unknown stresses. Once the three fictitious stresses $P_{x^{*}}^{i}, P_{y^{*}}^{i}, P_{z^{*}}^{i}$ are solved for, other stress components such as $\left(\sigma_{x^{*} x^{*}}^{i}\right)_{\text {in }},\left(\sigma_{y^{*} y^{*}}^{i}\right)_{\text {in }}$ and $\left(\tau_{x^{*} y^{*}}^{i}\right)_{\text {in }}$ induced by the above fictitious stresses can be calculated from the same expression by using $A_{x}^{i j}$ etc.. By the same method, all of the six stress components of the initial stresses at a specified point $k$ under 
the assumed arbitrary horizontal plane, $\left(\sigma_{x^{*} x^{*}}^{k}\right)_{0}$ etc., can be calculated through an equation with the same form as Equation (7) but with an appropriate set of new influence coefficients.

Rock masses are typically heterogeneous and contain discontinuities such as faults. To adequately estimate the state of stress properly the effects of inhomogeneity must be considered in certain cases [13].

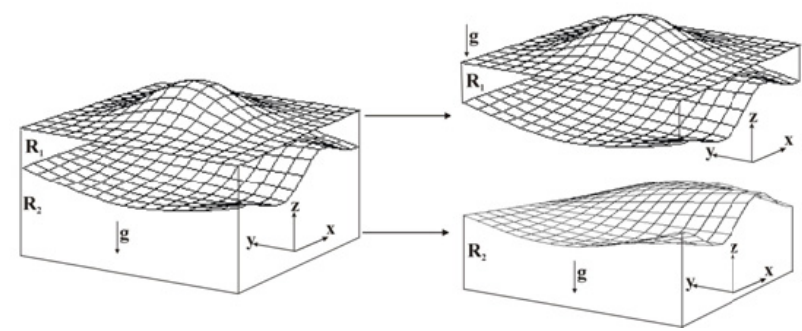

Figure 2. Conceptual model for calculating the stress state in an inhomogeneous body containing two subregions R1 and R2 (The topographic surface and the interfaces with local coordinate systems are tiled with boundary elements).

Figure 2 shows an inhomogeneous rock mass containing two subregions $R_{1}$ and $R_{2}$. The two subregions are each assumed to be homogeneous, isotropic and linear elastic. The common portions of the two subregions define the interface between the subregions. The local $x^{*}, y^{*}, z^{*}$ coordinate systems associated with the interfaces appear as shown in Figure 2. The local coordinates $x_{R 1}^{*}, z_{R 1}^{*}$ and $x_{R 2}^{*}, z_{R 2}^{*}$ are oppositely directed along the interfaces, i.e. $x_{R 1}^{*}=-x_{R 2}^{*}$ and $z_{R 1}^{*}=-z_{R 2}^{*}$. The areas must extend sufficiently far away from the area of interest such that the behaviour in that area is not greatly affected by perimeter of the R1-R2 interface. The upper subregion can be solved by the method above for the homogeneous half-plane with a free topographic surface. The lower subregion with the interface can be treated as the same problem expressed by Equation (7), except that the free topographic surface is replaced by the interface between the two subregions. Tractions and displacements must be continuous along the interface between the two subregions, we can have the following equations for the three stress components $\sigma_{z^{*} z^{*}}^{j} \tau_{v^{*} z^{*}}^{j}, \tau_{z^{*} x^{*}}^{j}$ at element $j$ along the interface

$\sigma_{z^{*} z^{*}}^{\left[\mathrm{R}_{1}\right]}(j)=\sigma_{z^{*} z^{*}}^{\left[\mathrm{R}_{2}\right]}(j)$

$\left.\tau_{y^{*} z^{*}}^{\left[\mathrm{R}_{1}\right]}(j)=-\tau_{y^{*} z^{*}}^{\left[\mathrm{R}_{2}\right]}(j)\right\}$

$\tau_{z^{*} x^{*}}^{\left[\mathrm{R}_{1}\right]}(j)=\tau_{z^{*} x^{*}}^{\left[\mathrm{R}_{2}\right]}(j)$

and

$u_{z^{*}}^{\left[\mathrm{R}_{1}\right]}(j)=-u_{z^{*}}^{\left[\mathrm{R}_{2}\right]}(j)$

$u_{y^{*}}^{\left[\mathrm{R}_{1}\right]}(j)=u_{y^{*}}^{\left[\mathrm{R}_{2}\right]}(j)$

$u_{x^{*}}^{\left[\mathrm{R}_{1}\right]}(j)=-u_{x^{*}}^{\left[\mathrm{R}_{2}\right]}(j)$

for the displacement. The minus signs in Equation (9) and (10) are a consequence of the opposite directions of the local coordinates of subregions $\mathrm{R}_{1}$ and $\mathrm{R}_{2}$ along the interface. This method can be extended to solve problems involving several homogeneous, isotropic and linear elastic subregions. However, this means that we will have to solve the boundary integral equations with a large number of coefficients. To save the requirement on central memory for boundary element simulation, a simultaneous equation solution method developed by Beer and Watson can be adopted [14]. Since in this study only two homogeneous subregions were represented, the procedure of Beer and Watson was not adopted.

\subsection{Check of the inhomogeneous modelling code}

Liu CL, Li G, Kuriyama K. and Mizuta Y [13] carried out numerical calculation using their BEM code developed for inhomogeneous modelling. They took the infinite model including concentric double cylindrical surfaces whose lengths are finite. As shown in Fig. 3, the inner boundary contour with radius $a$ is the free surface boundary subject to the uniform pressure and the outer boundary contour with radius $b$ is the interface between the subregion $R_{1}$ and $R_{2}$, where $R_{1}$ is the finite region between the free surface and the interface, and $R_{2}$ is the infinite region outside of the interface although the longitudinal length of those contours are $L$ (not infinite). They compared the numerical results with the analytical solution [15] and fund that the numerical and analytical solutions are almost the same even in the case of $L /(2 b)=2$. Please refer to Ref. 13 for further information about material parameters and solutions in detail.

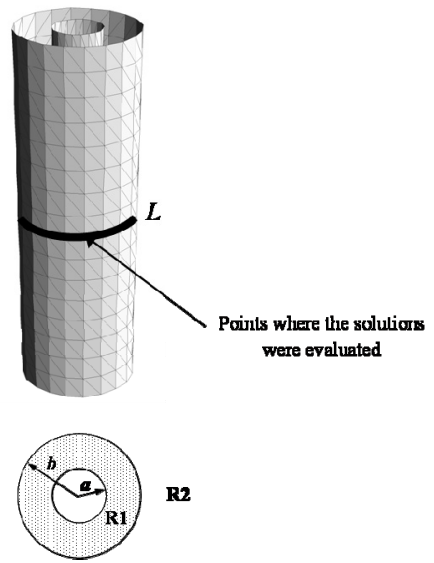

Figure 3. Axi-symmetric model containing two subregions.

\section{Application to the stress field determination for underground research laboratory}

\subsection{Introduction of Mizunami Underground Research Laboratory (MIU) and Tono district}

One aim of the geological disposal policy in Japan is the establishment of Underground Research Laboratories (URLs). The URLs are distinguished from a disposal facility, as outlined in the Atomic Energy Commission (AEC) report [16]. Research on the deep geological environment will provide the scientific and technological basis for R\&D on geological disposal of high-level radioactive waste. The AEC also 
stipulated that research at the underground laboratories contribute to Japan's scientific research on the geological environment. URL projects of the Japan Atomic Energy Agency (JAEA) are directed towards improving the reliability of geological disposal technologies and developing advanced safety assessment methodologies.

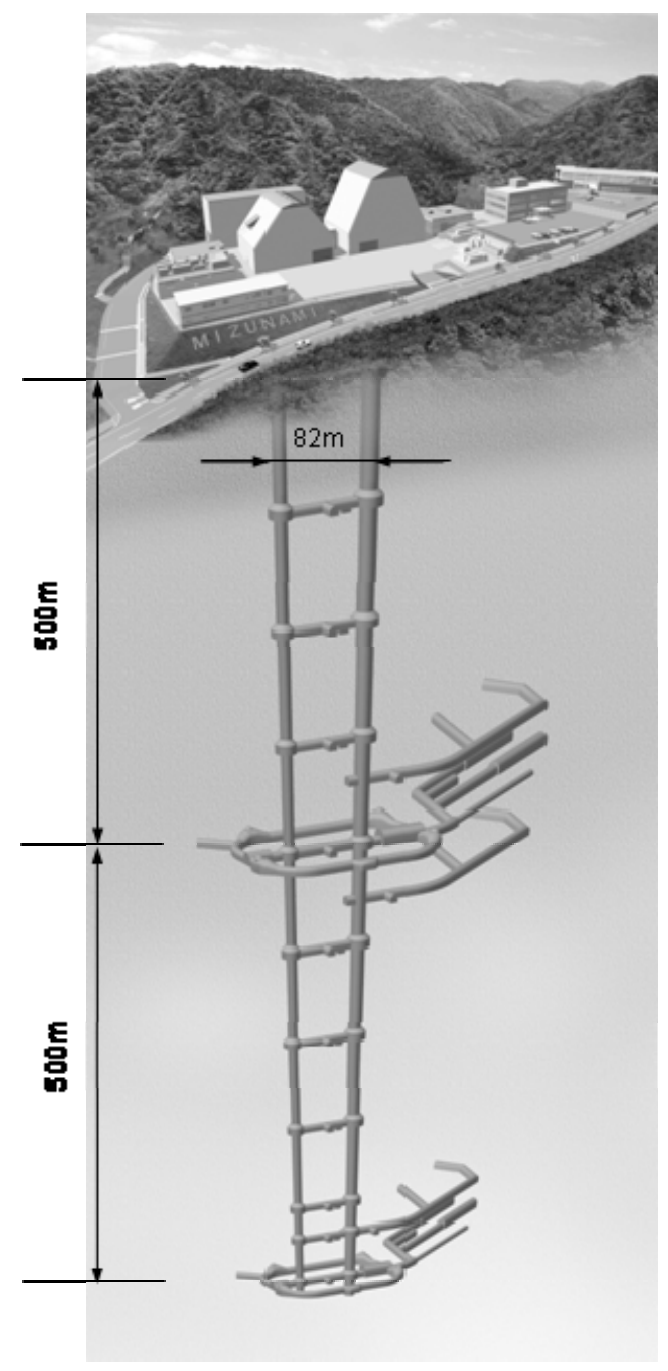

Figure 4. Diagram of the Mizunami Underground Research Laboratory (MIU).

As a part of the projects, the Mizunami Underground Research Laboratory (MIU), located in Mizunami city of Gifu Prefecture in central Japan, is under construction for research works 1,000 meters underground (see Fig. 4). The construction includes two vertical shafts excavated $1,000 \mathrm{~m}$ deep underground and horizontal tunnels at depths of 500 meters and 1,000 meters. First stage excavation of the vertical shafts to $300 \mathrm{~m}$ depth has already been carried out. The laboratory shall be utilized as a base for research of rock mechanics and groundwater flow relating to deep geological repositories.

Figure 5 shows the location of MIU in Tono district. Local hills reach elevations of 200 meters to 300 meters. Two main geologic units exist at MIU, a basement of Toki granite and the overlying Akeyo formation of mudstone and sandstone, which has a maximum thickness of $\sim 150$ meters [17]. The Tsukiyoshi fault is a reverse fault with a strike of N80W, a dip of 60 and an estimated throw of about $30 \mathrm{~m}$ located in Tono district.

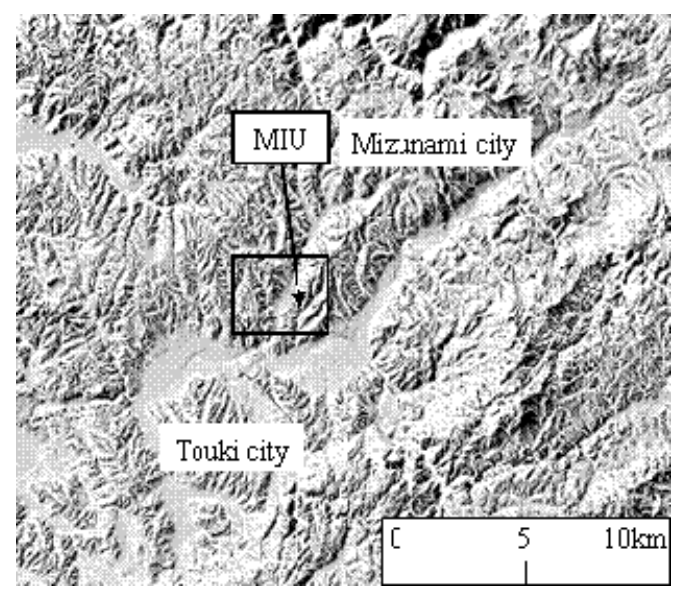

Figure 5. Location of MIU in Tono district. The rectangle indicates the area to be simulated.

\subsection{Local stress measurements using conventional hydraulic fracturing}

Rock stress measurements have been performed at 247 points under 9 different locations within Tono district by various measurement techniques, including the hydraulic fracturing (HF) [17], deformation rate analysis (DRA), and acoustic emission (AE). However, only the in-situ stresses measured by $\mathrm{HF}$ are introduced into the left column of Equation (5). Figure 6 shows the locations of the boreholes for stress measurement at locations 1 to 9 relative to the location of the Mizunami Underground Research Laboratory (MIU). Table 1 shows the in-situ stresses measured by HF at 101 points in different locations at various depths. Note that stress convention in this paper is that tensile stresses are considered positive and compressive stresses negative.

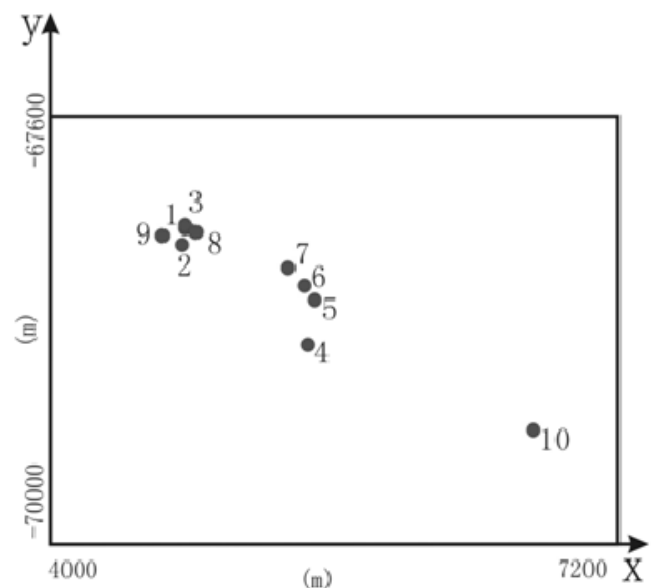

Figure 6. Map of measurement locations within the area of simulation shown in Fig. 5. The y-axis points north and the $\mathrm{x}$-axis points east. Point 10 shows MIU. 
Table 1. In-situ measured stresses for the Tono district

\begin{tabular}{|c|c|c|c|c|}
\hline $\begin{array}{l}\text { Measurement } \\
\text { locations }\end{array}$ & $\begin{array}{c}\text { Depth } \\
\text { (m) }\end{array}$ & $\begin{array}{c}\sigma_{1} \\
(\mathrm{Mpa})\end{array}$ & $\begin{array}{l}\sigma_{2} \\
\text { (Mpa) }\end{array}$ & $\begin{array}{c}\text { Degree of } \sigma_{1} \\
\text { (clockwise, } \\
\text { from north) }\end{array}$ \\
\hline \multirow[t]{9}{*}{1} & 233.6 & -7.26 & -12.16 & -46.69 \\
\hline & 235.5 & -6.97 & -11.85 & -71.46 \\
\hline & 238.5 & -8.45 & -15.78 & -70.02 \\
\hline & 249.9 & -5.80 & -9.89 & -25.78 \\
\hline & 251.8 & -5.71 & -9.47 & -14.32 \\
\hline & 253.0 & -5.70 & -9.42 & -23.27 \\
\hline & 258.9 & -5.97 & -9.66 & -39.95 \\
\hline & 260.9 & -5.55 & -8.85 & -27.12 \\
\hline & 263.9 & -5.95 & -9.45 & -23.14 \\
\hline \multirow[t]{10}{*}{2} & 52.3 & -1.00 & -1.40 & 45.20 \\
\hline & 64.5 & -1.70 & -3.30 & 65.20 \\
\hline & 77.0 & -1.40 & -2.40 & 35.40 \\
\hline & 102.0 & -1.90 & -3.20 & 26.60 \\
\hline & 122.0 & -6.20 & -12.50 & -89.60 \\
\hline & 141.0 & -7.50 & -11.40 & -72.80 \\
\hline & 157.8 & -6.60 & -11.40 & -46.00 \\
\hline & 170.3 & -3.40 & 4.80 & -42.60 \\
\hline & 184.2 & -10.10 & -20.20 & -51.30 \\
\hline & 192.5 & -4.50 & -8.30 & -61.00 \\
\hline \multirow[t]{11}{*}{3} & 39.0 & -1.00 & -2.20 & 32.30 \\
\hline & 44.0 & -1.50 & -1.90 & -36.70 \\
\hline & 75.0 & -1.80 & -3.80 & -13.80 \\
\hline & 79.0 & -1.70 & -3.30 & -20.40 \\
\hline & 87.0 & -1.40 & -1.80 & -38.80 \\
\hline & 105.0 & -2.10 & -3.70 & 22.30 \\
\hline & 127.0 & -2.10 & -4.00 & -28.10 \\
\hline & 162.0 & -3.60 & -5.30 & 32.50 \\
\hline & 188.5 & -3.20 & -5.40 & -50.50 \\
\hline & 199.0 & -3.90 & -6.30 & -18.90 \\
\hline & 205.0 & -4.50 & -6.50 & -58.50 \\
\hline \multirow[t]{16}{*}{4} & 49.0 & -2.90 & -5.10 & 0.40 \\
\hline & 199.0 & -6.80 & -14.10 & 3.80 \\
\hline & 249.0 & -9.10 & -20.30 & 10.70 \\
\hline & 309.0 & -3.80 & -4.80 & -40.20 \\
\hline & 351.0 & -8.80 & -17.50 & -26.80 \\
\hline & 404.0 & -10.40 & -19.20 & -32.50 \\
\hline & 498.5 & -13.60 & -28.00 & -55.90 \\
\hline & 564.0 & -14.10 & -29.70 & -50.90 \\
\hline & 600.0 & -15.80 & -25.30 & -39.90 \\
\hline & 651.0 & -16.10 & -29.20 & -36.10 \\
\hline & 700.0 & -12.90 & -20.80 & -41.20 \\
\hline & 790.0 & -15.70 & -22.80 & -41.40 \\
\hline & 850.0 & -18.40 & -28.30 & -45.40 \\
\hline & 900.0 & -25.50 & -48.50 & -53.30 \\
\hline & 941.0 & -23.40 & -42.70 & -27.50 \\
\hline & 991.0 & -18.30 & -27.80 & -71.30 \\
\hline \multirow[t]{6}{*}{5} & 233.6 & -7.26 & -12.16 & -46.69 \\
\hline & 235.5 & -6.97 & -11.85 & -71.46 \\
\hline & 238.5 & -8.45 & -15.78 & -70.02 \\
\hline & 249.9 & -5.80 & -9.89 & -25.78 \\
\hline & 251.8 & -5.71 & -9.47 & -14.32 \\
\hline & 253.0 & -5.70 & -9.42 & -23.27 \\
\hline
\end{tabular}

Sano, Ito, Hirata and Mizuta [18] reviewed methods of measuring stress and uncertainties in HF. The shut-in pressure, $p_{\mathrm{s}}$, is widely considered to equal the minimum principal stress $S_{\mathrm{h}}$ in the plane perpendicular to the borehole. In conventional $\mathrm{HF}$ analyses, the maximum principal stress $\left(S_{\mathrm{H}}\right)$ is determined through the following equation:

$$
S_{\mathrm{H}}=3 S_{\mathrm{h}}-p_{\mathrm{r}}-p_{\mathrm{p}}
$$

where $p_{\mathrm{r}}$ is the reopening pressure and $p_{\mathrm{p}}$ is the pore pressure. Equation (11) assumes that a hydraulic fracture closes completely before reopening. In order for Equation (11) to apply, the "flow rate should be sufficiently high to prevent fracturing fluid percolation into the closed fracture before the actual mechanical fracture reopening" [19]. However, the residual aperture of the induced fracture cannot be negligible for rocks [20-23]. Numerical simulations indicate that the pressurized fluid should permeate easily into a hydraulic fracture, even for an initial aperture of $3 \mu \mathrm{m}$ and the aperture should be enlarged by the penetration of fluid [24]. Equation (11) should be modified by substituting $p_{\mathrm{r}}$ into $p_{\mathrm{p}}[24,25]$ as

$$
2 p_{\mathrm{r}}=3 S_{\mathrm{h}}-S_{\mathrm{H}}
$$

Based on experimental results for a granitic rock mass, Pine et al. [26] considered reopening pressure as a measure of minimum horizontal stress, namely,

$$
2 p_{\mathrm{r}}=S_{\mathrm{h}}
$$

Ito and Hayashi [27] numerically showed that the conventional $p_{\mathrm{r}}$ could be equal to $p_{\mathrm{s}}$ by considering that the pressure fluid permeates the fracture deeply before reopening. Rutqvist et al. [28] suggested that Equations (11), (12), and (13), might be true for fracture with extremely small apertures, medium apertures and sufficiently large apertures, respectively.

In general, numerical simulations $[25,27,28]$ suggest that water permeates hydraulic fractures at a lower pressure than conventional reopening pressure, and that $p_{\mathrm{r}}$ is affected by flow rate. The magnitude of $p_{\mathrm{r}}$ should also be affected by water volume in the pressurizing system [24]. When the constant flow rate is so small that the pressure gradient in the fracture is negligible, temporal variation of pressure are given by [23],

$$
\mathrm{d} p / \mathrm{d} t=\mathrm{Q} /(\mathrm{d} V \mathrm{c} / \mathrm{d} p+C)
$$

where $Q, V$ c and $C$ are flow rate, volume change due to fracture opening and compliance of the system, respectively. Since the conventional $p_{\mathrm{r}}$ could only be detected when the water permeated a fracture several times longer than the borehole radius, this result explained why the conventional $p_{\mathrm{r}}$ is almost equal to $p_{\mathrm{s}}$. Ito et al. also proposed the use of a highstiffness HF system instead of a compliant conventional HF system.

As it is not easy to make a HF system sufficiently rigid for measurements in a deep borehole, the authors used the conventional HF procedure for local stress measurements described in this paper. However, in the measurements at the MIU, the flow meter was installed at the position of the straddle packer and the flow rate at that position was controlled in the fracture reopening procedure, while the flow meter is put at the ground surface in the conventional HF procedure. The measurements at the MIU were carried out recently whereas the measurements at other locations were carried out before $21^{\text {st }}$ century.

\subsection{Estimation of field stress state by 3-D BEM}

The BEM model for the Tono district simulates an area 3.2 $\mathrm{km}$ long and $2.4 \mathrm{~km}$ wide. The BEM element (see Fig. 7) generally is an isosceles-right triangle with $200 \mathrm{~m} \times 200 \mathrm{~m}$ in both directions, while the elements that cover most fieldmeasured locations are finely discretized $(100 \mathrm{~m} \times 100 \mathrm{~m})$ to improve the accuracy of stress calculations. Interface elements simulate the boundary between different geologic units, here the Akeyo formation and the Toki granite. The sub region between the surface and the interface in Figure 7 represents the Akeyo formation, while the sub region under the interface represents the Toki granite. The Tsukiyoshi fault is modelled with Displacement Discontinuity Method (DDM) joint elements [9]. Elastic constants and densities of the formations were determined by laboratory tests of core specimens taken from various locations at various depths. 
However, the averaged values shown in Table 2 are adopted in numerical modelling.

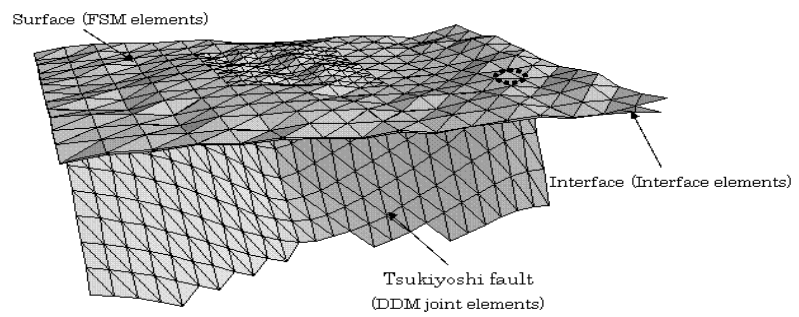

Figure 7. Grid of triangular elements for the BEM modeling. The volume modelled has a plan view area of $3.2 \mathrm{~km} \times 2.4 \mathrm{~km}$ and a depth of $1.2 \mathrm{~km}$. The projection of MIU onto the surface is shown by a dotted line.

\begin{tabular}{|c|c|c|c|c|c|}
\hline \multicolumn{3}{|c|}{ Materials } & \multirow{2}{*}{$\begin{array}{c}\text { Akeyo formation } \\
2.21\end{array}$} & \multirow{2}{*}{$\begin{array}{c}\text { Toki granite } \\
50.09\end{array}$} & \multirow[t]{2}{*}{$\begin{array}{l}\text { Tsukiyoshi fault } \\
\text { s }\end{array}$} \\
\hline Young's modulus & $\bar{E}$ & [GPa] & & & \\
\hline Poisson's ratio & $\nu$ & & 0.30 & 0.35 & \\
\hline Density & $\rho$ & {$\left[\mathrm{g} / \mathrm{cm}^{3}\right]$} & 1.84 & 2.56 & \\
\hline Normal stiffness & $k_{n}$ & {$[\mathrm{MPa} / \mathrm{m}]$} & & & 50.0 \\
\hline Shear stiffness & $k_{s}$ & {$[\mathrm{MPa} / \mathrm{m}]$} & & & 50.0 \\
\hline
\end{tabular}

Model parameters are based on a combination of field measurements and results from numerical simulations. The mean inclination of Tsukiyoshi Fault is 56.3 degree. The mean vertical dimension of the fault that is obtained from boring data is $23.8 \mathrm{~m}$ and thus, the mean thickness of the fault, $t$, is $13.2 \mathrm{~m}$. The $\mathrm{P}$ wave velocities in the fault have been found from logging data to be 65.3 77.4\% (mean ratio, $r_{p}=0.717$ ) of that of the sound rock. Assuming that the normal stiffness $k_{n}$ and shear stiffness $k_{s}$ are given by the following formula:

$k_{n}=\frac{E_{F}}{t}, k_{s}=\frac{E_{F}}{2(1+v) t}$, and $E_{F}=r_{p}^{2} E_{\text {core }}$

where $E_{\text {core }}$ is Young's modulus measured from core specimens, then, $k_{n}=86 \mathrm{MPa} / \mathrm{m}, k_{s}=33 \mathrm{MPa} / \mathrm{m}$ for the fault in the Akeyo formation and $k_{n}=1950 \mathrm{MPa} / \mathrm{m}$, $k_{s}=722 \mathrm{MPa} / \mathrm{m}$ for the fault in the Toki granite. However, normal and shear stiffness of the DDM joint elements are both assumed to be $50 \mathrm{Mpa} / \mathrm{m}$, because our FEM modelling yields stress distribution in the Toki granite that are gross inconsistent with the measured values, unless stiffnesses of 50 MPA are used [19].
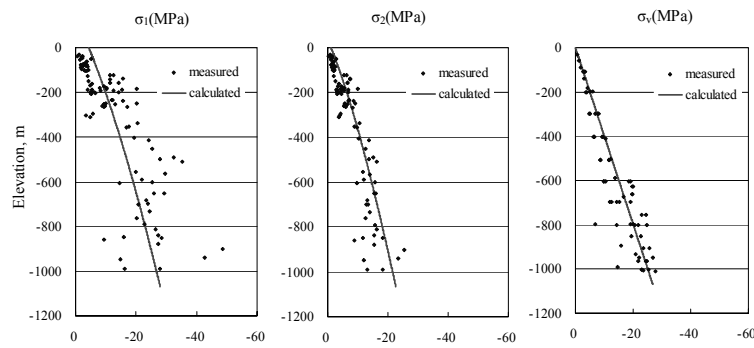

Figure 8. In-situ stresses versus depth for the Tono district
In Equation (5), 6 coefficients are unknown since $\alpha_{x}, \quad \alpha_{y}$ and $\alpha_{z}$ are known, while 101 stress measurements exist. Only vertical stresses were determined from DRA and $\mathrm{AE}$, and the measured values were compared with overburden pressure, $\rho g h$. HF can only determine the stress states in the plane perpendicular to the vertical holes (see Table 1 and Fig. 8). Hence, data of $\sigma_{z}, \tau_{y z}$ and $\tau_{z x}$ components are not in the left column of Equation (5). Furthermore, there are no sudden changes in the stresses determined from Equation (2), although sudden changes near the ground surface or subsurface are in the calculated stresses through FLAC 3D (see Fig.9).
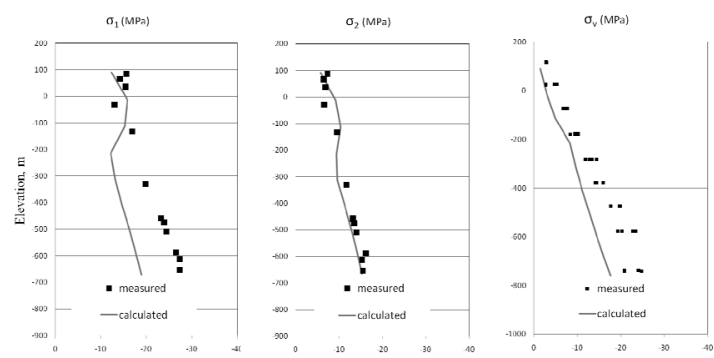

Figure 9. The local stress distributions calculated by FLAC3D forward analysis compared with the measurement results at location 6 of Fig. 6.

Based on the measurement results and material properties adopted above, we first used BEM method to calculate the matrix of induced state of stresses in Equation (5). Second we used a simplex method [29] to determine the two constants $a$ and $b$ in Equation (2), with $a=904.6$ meters and $b=812.1$ meters. A least squares approach is chosen to control the distribution of error and find the best approximate solution for this over-determined problem [29, 30]. Table 3 shows the calculated results for far field stress state. The solution for the far field stresses with the non-linear assumption of the initial state of stresses is affected by local effects such as nonlinearity and large strains. Furthermore, the fault stiffness adopted from the FEM modeling results might be a key factor that would contribute to error in the BEM modeling. Finally, there still exists the possibility that one of the principal stresses is not vertical.

\begin{tabular}{|c|c|}
\hline$S_{x}(\mathrm{MPa})$ & -1.99 \\
\hline$S_{y}(\mathrm{MPa})$ & -3.45 \\
\hline$S_{x y}(\mathrm{MPa})$ & 0.755 \\
\hline$k_{x}$ & 0.778 \\
\hline$k_{y}$ & 0.674 \\
\hline$k_{x y}$ & -0.168 \\
\hline $\boldsymbol{\alpha}_{\mathbf{x}(\text { Akeyo })}$ & 0.429 \\
\hline $\boldsymbol{\alpha}_{y(\text { Akcyo })}$ & 0.429 \\
\hline $\boldsymbol{\alpha}_{z(\text { (Akyo) })}$ & 1 \\
\hline $\boldsymbol{\alpha}_{\mathbf{x}(\mathrm{Tok})}$ & 0.538 \\
\hline $\boldsymbol{\alpha}_{y(\mathrm{~T} \mathrm{Tok})}$ & 0.538 \\
\hline $\boldsymbol{\alpha}_{\text {(Troki) }}$ & 1 \\
\hline$a$ & $904.6 \mathrm{~m}$ \\
\hline$b$ & $812.1 \mathrm{~m}$ \\
\hline
\end{tabular}


Fig. 8 shows the far-field principal stresses, calculated using the BEM results and the coefficients for equations 2 and 5 , as a function of elevation. The vertical stress $\sigma_{v}$ has a stress gradient of $0.026 \mathrm{MPa} / \mathrm{m}$. The calculated stresses are calculated based on in-situ measured stresses shown in Table 1. In most cases the absolute values of measured horizontal principal stresses, $\sigma_{1}$ and $\sigma_{2}$, exceed those of the vertical stresses at shallow depths. The above results show that the stress state measured varied with depth from thrust fault type $\left(\left|\sigma_{1}\right|>\left|\sigma_{2}\right|>\left|\sigma_{V}\right|\right)$ to strike-slip fault type $\left(\left|\sigma_{1}\right|>\left|\sigma_{V}\right|\right.$ $\left.>\left|\sigma_{2}\right|\right)$.

\subsection{Estimation of field stress state by 3-D FDM with boundary conditions determined by the above BEM analysis}

To illustrate how the above far field stress coefficients can be adopted as input boundary conditions, a three-dimensional finite difference method named FLAC3D (Fast Lagrangian Analysis of Continua in 3-Dimensions) [31] is applied to simulate the same area of 3-D BEM analysis. FLAC3D can solve a wide range of complex problems in mechanics, and has some advantages over a BEM approach in certain situations, such as modelling of the non-linear behaviour of materials and large-strain deformation analysis. The region modeled is $3.2 \mathrm{~km}$ long, $2.4 \mathrm{~km}$ wide and $1.1 \mathrm{~km}$ deep. The model was composed of 280,160 elements and 301,704 gridpoints with an interface to simulate the Tsukiyoshi fault. The Akeyo formation and Toki granite are accounted for in the simulation; their properties are shown in Table 2.

A stress boundary determined by the above-calculated coefficients of far field stresses is applied to the FLAC3D model. In FLAC3D forces or stresses may be easily applied to any boundary by some inherent commands. The boundaries should be placed sufficiently far away from the area of interest such that the behaviour in that area is not greatly affected, with constraints on memory and computer time being considered. In this study a space about 300 meters between the boundaries and the areas of interest is adopted (see Fig. 6). Fig. 9 shows the stresses calculated with FLAC3D at location 6 (in Fig. 6) with the measured stresses. We can tell that calculations with FLAC3D provide a better fit at shallow depths than at great depth, which could be a result of more input data, i.e., in-situ measurement results, at shallow depths (see Table 1). The least square procedure adopted to solve Equation (5) for the unknown coefficients reflects the influence of field measurements at shallow depths better than those at great depths. The estimated stresses distribution has the same pattern as the measured stresses, i.e., the absolute value of the vertical stress is least at shallow depths and increases with depth.

All the stress measurements at the locations 1-9 were carried out before $21^{\text {st }}$ century by the conventional HF method and those HF data were used for stress field estimation at location 10, which is the location of the Mizunami Underground Research Laboratory (MIU). We assumed that locations 1-10 were under the influence of the same far-field stress state, i.e., the estimation results of the above BEM modelling. Therefore the unknown stress state at location 10 could be estimated based on the FLAC3D model with boundary conditions determined by the above BEM analysis. Recently the stress measurements at the MIU were carried out by the improved HF method, which provided us a chance to verify our estimation of the stress state at location 10 .

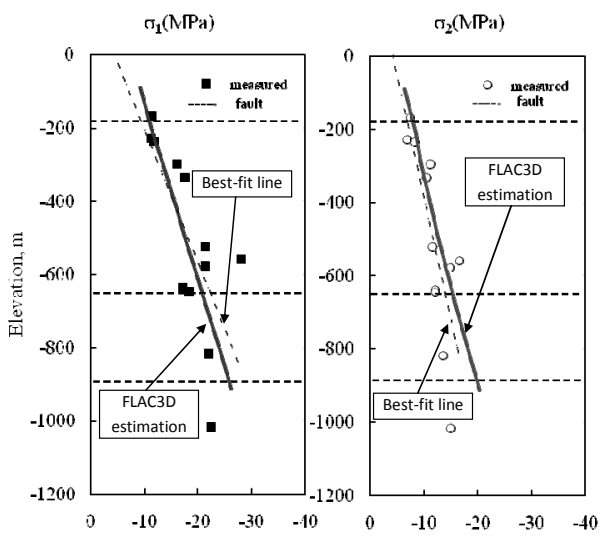

Figure 10. In situ stresses measured by hydraulic fracturing at depths as great as $1000 \mathrm{~m}$ at MIU (location 10 in Fig. 6) compared with the stresses estimated using FLAC3D. The horizontal dashed lines show where the MIU borehole intersects three small faults.

Figure 10 shows stresses estimated using FLAC3D compared with the in situ stresses measured by hydraulic fracturing at MIU at depths as great as $1,000 \mathrm{~m}$. The horizontal dashed lines in Fig. 10 show where the MIU borehole intersects three small faults that were not modelled in our numerical simulations. When we compare the estimated stresses with the measured ones, good matches can be found for both the maximum and minimum principal stresses as shown in Fig. 10, which means that it is practical to estimate the stress state at MIU (location 10) based upon the in-situ stress measurement results at locations 1-9. Therefore, the method proposed here provides a practical way to estimate the stress state based on measured results with reasonable predetermined boundary conditions by BEM analysis. Since the FLAC3D model is only about $1.1 \mathrm{~km}$ in depth, the stress state estimated at greater depth, i.e., more than $1000 \mathrm{~m}$, deviates from the measurement results due to the influence of the bottom boundary. A model with greater depth at least 1200 meters will be necessary for accurate estimation of stress state at depth near 1000 meters. A best-fit line for the in situ measurement data was added in this figure to compare with the FLAC3D estimated results. The FLAC3D estimation fits the measurement data better than the best-fit line at shallow depth.

Thus, by adopting the stress boundary determined by nonlinear far field stress coefficients calculated from BEM modelling, the in situ state of stress can be calculated by FDM simulation considering tectonic stresses, inhomogeneity and discontinuities of rock mass. With the understanding of this initial state of stress we can easily study other aspects that we are interested in along with the excavation of Mizunami Underground Research Laboratory, although more detailed 
field formation should be taken into modelling for better estimation of the local stresses.

\section{Conclusion}

A new proposal for the determination of the far field stresses based on stress measurement results is developed in this paper. The method considered the tectonic stresses, topography and inhomogeneity of the rock mass. The in situ measurement stress is decomposed into tectonic and gravitational components, and 6 independent far field stress coefficients are achieved by back analysis using newly developed three-dimensional BEM simulation incorporating inhomogeneity for determination of gravitational stresses distribution.

The 3-D BEM and FDM applications to the MIU site have shown that the estimated stresses agree well with the tendency of the in situ measurement data. Therefore, it is practical to estimate the stress state in an unknown location based upon the in situ measurement data in the close locations by inverse analysis. It is likely that the tectonic stresses have to be considered for a better estimation of underground stress distribution in tectonically active region, such as in Japanese islands. The method described here provides boundary conditions for commercially available FEM or FDM programs by considering the influence of tectonic stresses based on stress measurements.

\section{References}

[1] Matsuki K, Kato T, Kimura N, Nakama S, Sato T. Estimation of regional stress for heterogeneous rock mass by FEM. Proc. of the ISRM Int. Symposium $3^{\text {rd }}$ ARMS. 2004. p. 1135-1140.

[2] Savage WZ, Swolfs HS, Powers PS. Gravitational stresses in long symmetric ridges and valleys. Int $\mathrm{J}$ Rock Mech Min Sci Geomech Abstr 1985. 22, p. 291-302.

[3] Jaeger, JC, Cook, NGW. Fundamentals of Rock Mechanics, Chapman and Hall LTD and Science Paperbacks, 1971.

[4] Brown ET, Hoek E. Trends in relationships between measured in-situ stresses and depth. Int J Rock Mech Min Sci Geomech Abstr 1978. 15, p. 211-215.

[5] Kanagawa T, Hibino S, Ishida T, Hayashi M, Kitahara Y. In situ stress measurements in the Japanese islands: over-coring results from a multi-element gauge used at 23 sites. Int J Rock Mech Min Sci Geomech Abstr 1986. 23, p. 29-39.

[6] Amadei B, Stephanson O. Rock mechanics for underground mining, 2nd ed. London: Chapman \& Hall, 1993.

[7] Cornet FH, Valette B. In situ stress determination from hydraulic injection test data. J. of Geophysical Research. 1984. 89, p. $11,527-11,537$

[8] Becker AA. The boundary element method in engineering. McGraw-Hill, London, 1992.

[9] Crouch SL, Starfield AM. Boundary Element Methods in Solid Mechanics. 2nd end. George Allen and Unwin, London, 1983.

[10] Kuriyama K, Mizuta Y. Three-dimensional elastic analysis by the displacement discontinuity method with boundary division into triangular leaf element. Int. J. Rock Mech. Min. Sci. \& Geomech. Abstr. 1993. 30, p. 111-123.
[11] Kuriyama K, Mizuta Y, Mozumi H, Watanabe T. Threedimensional elastic analysis by the boundary element method with analytical integrations over triangular leaf elements. Int. J. Rock Mech. Min. Sci. \& Geomech. Abstr. 1995. 32, p. 77-83.

[12] Martel SJ, Muller JR. A two-dimensional boundary element method for calculating elastic gravitational stress in slopes. Pure appl. geophys. 2000. 157, p. 989-1007.

[13] Liu CL, Li G, Kuriyama K, Mizuta Y. Development of a computer program for inhomogeneous modelling using 3-D BEM with analytical integration and its application to rock slope stability evaluation. Int J Rock Mech Min Sci. 2005. 42, p. 137-144.

[14] Beer G, Watson JO. Introduction to finite and boundary element methods for engineers. John Wiley \& Sons Ltd. 1992.

[15] Hocking, G. Three-dimensional elastic stress distribution around the flat end of a cylindrical cavity. Int. J. Rock Mech. Min. Sci. \& Geomech. Abstr, 1976, 13, 331-337.

[16] Long-term program for research, development and utilization of nuclear energy (Unofficial Translation). AEC (2000). http://www.aec.go.jp/jicst/NC/tyoki/siryo/tyoki_e/siryoe. htm

[17] Nakama S, Sato T, Kato H. Status of study on in-situ stress in the Mizunami Underground Research Laboratory Project. Proceedings of the 40th U. S. Rock Mechanics Symposium, Alaska Rocks 2005. CD-ROM 05-887.

[18] Sano O, Ito H, Hirata A, Mizuta Y. Review of methods of measuring stress and its variations. Bull. Earthq. Res. Inst. Univ. Tokyo 2005. 80, p.87-103.

[19] Haimson BC, Cornet FH. ISRM suggested methods for rock stress estimation - Part 3: hydraulic fracturing (HF) and/or hydraulic testing of pre-existing fractures (HTPF). Int. J. Rock Mech. \& Min. Sci. 2003. 40, p.1011-1020.

[20] Bredehoeft J, Wolff R, Keys W, Shuter E. Hydraulic fracturing to determine the regional in situ stress field. Piceance Basin Colorado. Geol. Soc. 1976. 87, p.250-258.

[21] Zoback MD, Rummel F, Jung R, Raleigh CB. Laboratory hydraulic fracturing experiment in intact and pre-fractured rock. Int. J. Rock Mech. Min. Sci. \& Geomech. Abstr. 1977. 14, p.49-58.

[22] Cornet FH. Analysis of injection tests for in-situ stress determination. Proc. Workshop hydraulic fracturing stress measurement, Menlo Park. 1982. p.414-443.

[23] Durham WB and Bonner BP. Self-propping and fluid flow in slightly offset joints at high effective pressures. J. Geophys. Res. 1994. 99, p.9391-9399.

[24] Ito T, Evans K, Kawai K, Hayashi K. Hydraulic fracture reopening pressure and the estimation of maximum horizontal stress. Int. J. Rock Mech. Min. Sci. \& Geomech. Abstr. 1999. 36, p.811-826.

[25] Hardy MP and Asgian MI. Fracture reopening during hydraulic fracturing stress determination. Int. J. Rock Mech. Min. Sci. \& Geomech. Abstr. 1989. 26, p.489-497.

[26] Pine RJ, Ledingham P, Merrifield CM. In situ stress at Rosemanowes Quarry to depths of 2000m. Int. J. Rock Mech. Min. Sci. \& Geomech. Abstr. 1983. 20, p.63-72.

[27] Ito T, Hayashi K. Analysis of crack reopening behavior for hydrofrac stress measurement. Int. J. Rock Mech. Min. Sci. \& Geomech. Abstr. 1993. 30, p.4235-4240.

[28] Rutvist J, Tsang CF, Stephansson O. Uncertainty in the maximum principal stress estimated from hydraulic fracturing measurement due to the presence of the induced fracture. Int. J. Rock mech. Min. Sci. \& Geomech. Abstr. 2000. 37, p.107-120. 
[29] William M. Geophysical data analysis: Discrete inverse theory. Academic Press, 1989.

[30] Mizuta Y. Study on improved procedure for determination of three-dimensional distributions of the initial rock stresses (Third
Report), Japan Nuclear Cycle Development Institute. 2007. (in Japanese).

[31] Itasca Consulting Group, Inc. FLAC3D-Fast Lagrangian Analysis of Continua in 3 Dimensions. Version 2.0. User's Manual. Minneapolis, MN: Itasca. 1997. 